\title{
Clinical Considerations of Open Gingival Embrasures
}

\author{
Jae Hyun Park, Kiyoshi Tai, John Morris and Dorotea Modrin \\ Arizona School of Dentistry \& Oral Health, A. T. Still University \\ U.S.A.
}

\section{Introduction}

Gingival embrasures are defined as the embrasure cervical to the interproximal contact. ${ }^{1}$ If the embrasure space is not completely filled by the gingiva, it is considered open. Open gingival embrasures contribute to retention of food debris and can adversely affect the health of the periodontium. They are more common in adult patients with bone loss. ${ }^{2}$ Black triangles occur in more than $1 / 3$ of all adults and should be discussed with patients prior to initiating dental treatment.1,3 Key considerations in restorative and orthodontic treatment are preserving papilla and avoiding black triangles in the gingival embrasures of the esthetic zone (Figure 1). Open embrasures are best managed with a team work involving restorative, orthodontic and periodontal parts (Figure 2).

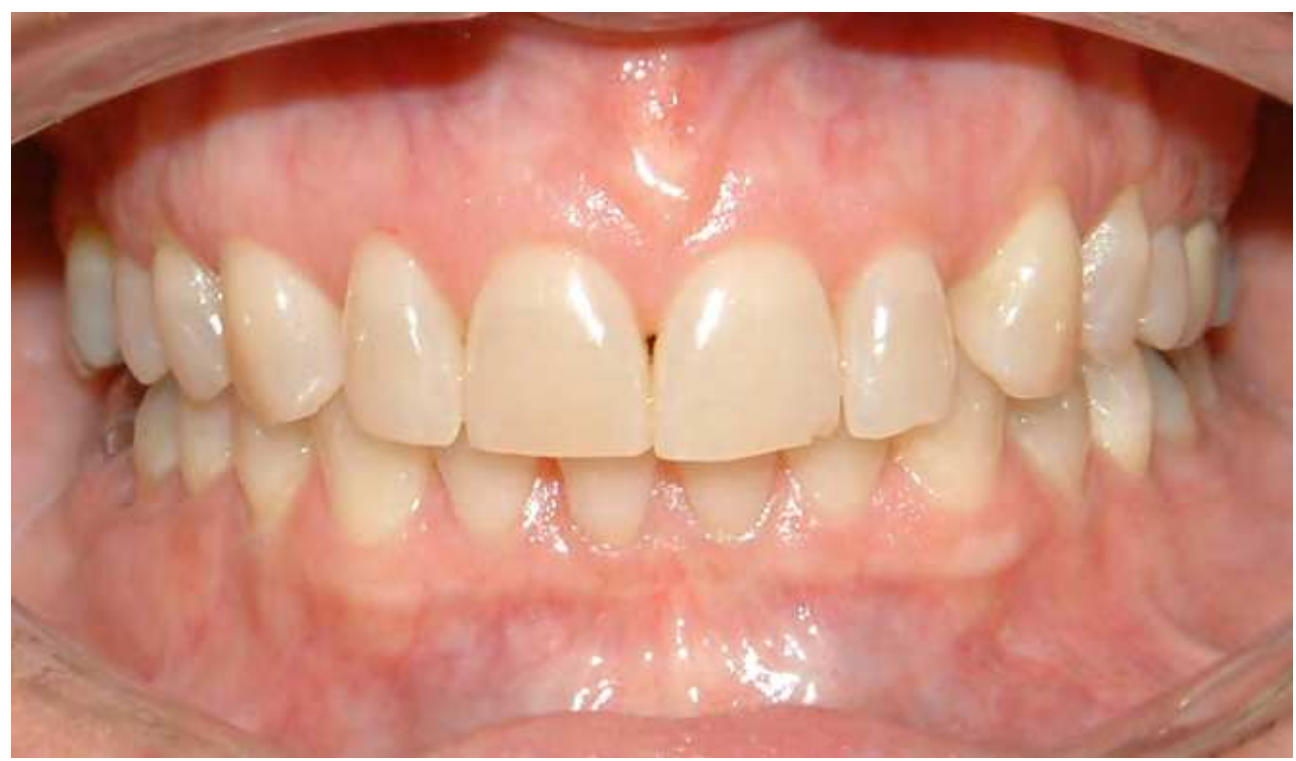

Fig. 1. Open gingival embrasure between the maxillary central incisors. 
Open gingival embrasures are visibly unesthetic and negatively affect a person's smile. In a study by Kokich et al., ${ }^{4}$ orthodontists considered a $2 \mathrm{~mm}$ open gingival embrasure as noticeably less attractive than an ideal smile with normal gingival embrasure. Open gingival embrasures slightly greater than $3 \mathrm{~mm}$ were considered less attractive by both general dentists and the general population.

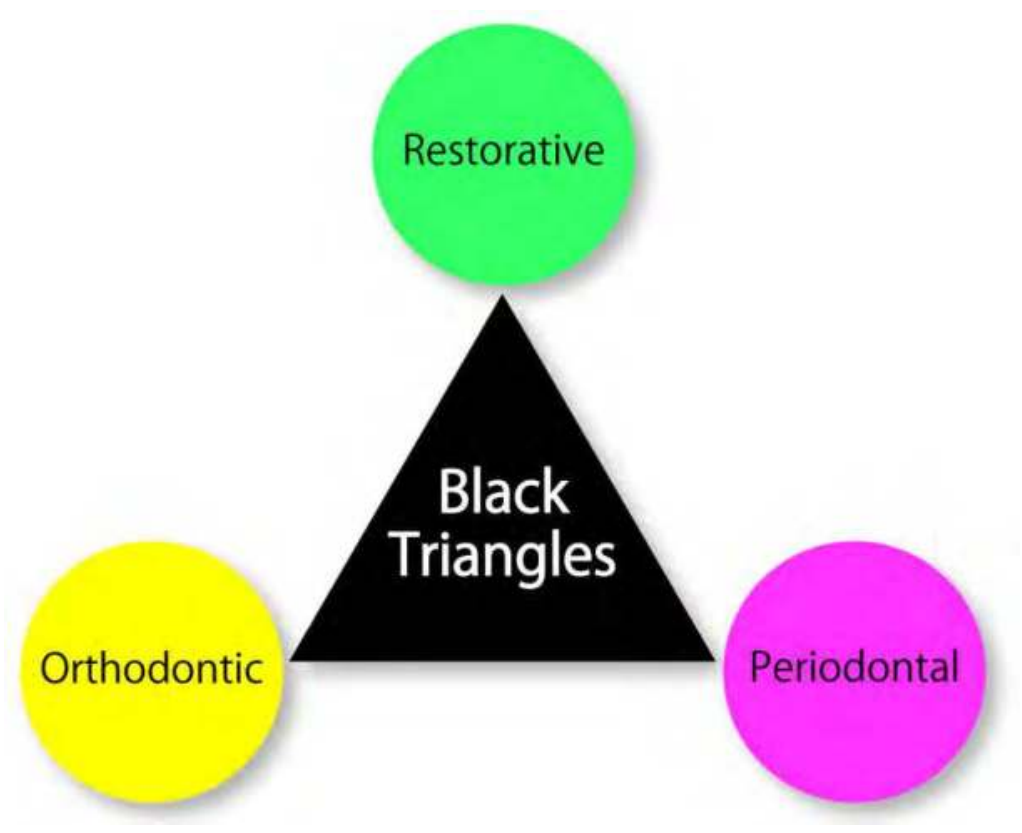

Fig. 2. Interdisciplinary approach to overcome black triangles.

To better manage open gingival embrasures, the dental clinician must be aware of the underlying etiology and make an individualized treatment plan for each patient. Many embrasures may be corrected with restorative procedures, but if the underlying etiology is not addressed correctly, the result may not be as esthetic as expected. ${ }^{5}$ Open gingival embrasures are more frequently encountered in adults undergoing orthodontic treatment $(38 \%)$ than adolescents in treatment $(15 \%) .{ }^{3}$ However, $41.9 \%$ of adolescent patients who are treated for maxillary incisor crowding have gingival embrasures. ${ }^{6}$ The higher prevalence in adults is related to periodontal disease and periodontal or orthognathic surgery.1,7 Gingival embrasures change over time, and once filled, embrasures may become open again. 8,9

\section{Etiology and prevalence of open gingival embrasures}

Etiologic factors for open gingival embrasures include; dimensional changes of papilla during orthodontic treatment, long lasting orthodontic treatment, loss of periodontal attachment resulting in recession, loss of height of the alveolar bone relative to interproximal contact, length of embrasure area, root angulations, age, contact position, and triangular-shaped crowns. ${ }^{10-12}$ Patients may present with one or more etiologic factor; thus, managing each patient requires an individual assessment and treatment plan. 
The occurrence of open gingival embrasures is found to be age related. Studies ${ }^{1,13}$ have demonstrated that patients over 20 are more susceptible than those under 20. Open gingival embrasures were reported in $67 \%$ of the population over 20 compared with $18 \%$ in the population under 20.1 This is due to the thinning of oral epithelium, a decrease in keratinization, and a reduction in papilla height as a result of the aging process. Therefore, age is a significant factor leading to wide and long embrasure spaces in adults. Embrasure and tooth morphology also is another etiologic factor. Open embrasures occur more frequently in short narrow, long narrow, long wide, and short wide embrasure morphologies.11,13

\section{Periodontal disease and open gingival embrasures}

Periodontal disease leads to loss of alveolar bone which also affects the interdental papilla. If the distance from the alveolar crest to interdental contact point exceeds $5 \mathrm{~mm}$, it is more likely that the papilla is insufficient to fill the embrasure. ${ }^{2}$ The distance between the contact point and the alveolar crest is less than $5 \mathrm{~mm}$ in healthy periodontium whereas, pocket depths greater than 3 $\mathrm{mm}$ will lead to increased plaque retention, inflammation, and possibly gingival recession. ${ }^{14}$ For those with periodontal diseases, it is the bone loss that increases the distance between the contact points and alveolar crest and eventually creates open gingival embrasures.

The distance from the base of the contact point to the alveolar crest in central incisors is a strong indicator of the presence of open gingival embrasures (Figure 3a). Tarnow et al. ${ }^{2}$ reported an association between black triangles and the distance from the contact point to the alveolar crest of the bone. Another study found that a distance of 5, 6, and $7 \mathrm{~mm}$ resulted in an open embrasure in 2, 44, and $73 \%$ of the cases, respectively. ${ }^{15}$ These observations indicated that papilla was present in almost $100 \%$ of the cases if the distance from the alveolar crest to the contact point was $5 \mathrm{~mm}$ or less. When the distance was more than 7 $\mathrm{mm}$, most cases had an open gingival embrasure. At $6 \mathrm{~mm}$, the papilla was present in half of the cases. ${ }^{15}$ Other studies ${ }^{14,16}$ have reported similar results (Figure $3 b$ ).

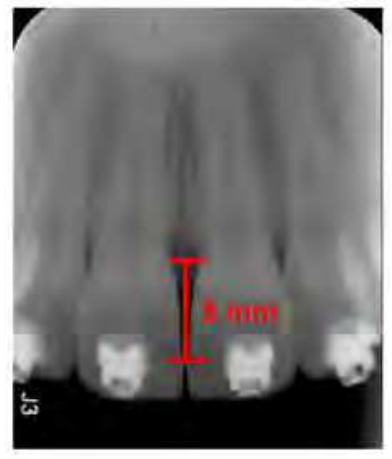

a

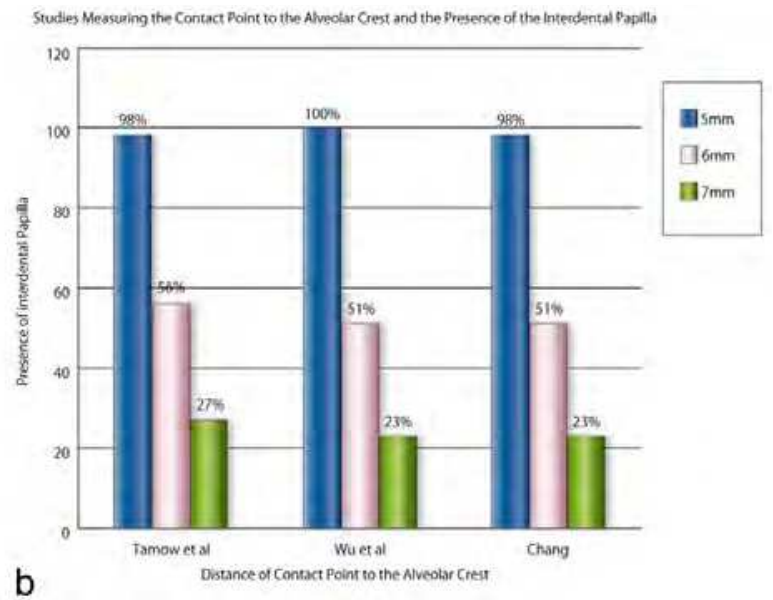

Fig. 3. (a) The distance between the alveolar crest to contact point (red) is critical in determining the extent of an open embrasure. A distance greater than $5 \mathrm{~mm}$ is considered to be a black triangle. (b) Summary of several studies measuring the distance from the alveolar crest to the contact point. Increasing the distance will increase the likelihood of an open embrasure. 
The prevalence of plaque accumulation and gingivitis is probably higher in people with crowding, but host susceptibility and other factors may also play a role in the occurrence of open gingival embrasures, especially in patients who have been previously treated for periodontal disease. ${ }^{17}$ For these patients, there needs to be an increased effort to enhance periodontal maintenance and oral hygiene to prevent bone loss and recession.

Adult patients with open gingival embrasures have an increased alveolar bone crestinterproximal contact distance of $5.5 \mathrm{~mm}$ or more. ${ }^{3}$ An increase of $1 \mathrm{~mm}$ in the distance between the alveolar bone crest and interproximal contact increases the possibility of an open gingival embrasure from 78 to $97 \%$. As a rule, 5-6 mm distance from the contact point to the alveolar crest is the most critical in determining the presence or absence of an open gingival embrasure. ${ }^{15}$

Chronic periodontitis and tooth brush trauma are other factors that may cause open embrasures. If tooth brushing is causing gingival recession, interproximal tooth brushing should be discontinued until the tissue can recover if it causes loss of interdental papilla.18 At present, there are no surgical procedures to augment papilla with a predictable outcome.19-25 Surgical papillary reconstruction often results in contraction and necrosis of the grafted tissue due to tissue fragility and the low blood supply to interdental papilla. ${ }^{15}$ However, case studies 26,27 have reported some degree of success with subepithelial connective tissue grafts and orthodontic therapy. Pedicle flaps have provided better results than free gingival grafts. ${ }^{15}$

Presence of a thick biotype gingiva and no loss of insertion at the periodontal attachment are important for the successful outcome of the surgery.18 Patients with a thin biotype of gingiva are more susceptible to recession and consequently, to open gingival embrasures. Patients with thin periodontium are shown to have long narrow maxillary central incisors, whereas patients with a thick biotype have short and wide central incisors. ${ }^{28}$ In addition, the thick periodontal biotype has a thick osseous structure with flat morphology and a thick gingival tissue with short wide papilla. Thick biotype is associated with less open embrasures especially around implants. ${ }^{29}$ In contrast, thin biotype is characterized by a scalloped appearance with long interdental papilla. ${ }^{30}$ Typically thick biotype has a better vascular supply and biological tissue memory that helps the tissue to rebound, whereas the thin biotype usually results in permanent recession. ${ }^{24}$ Once interdental gingival recession has occurred, there is a reduced height and thickness of free gingiva that results in a long clinical crown. This recession is aggravated by plaque and toothbrush trauma. Atraumatic plaque control is highly recommended for patients susceptible to black triangles. ${ }^{31}$

\section{Orthodontic correction of open gingival embrasures}

Root divergency of adjacent teeth is strongly associated with open gingival embrasures. This either occurs naturally or is caused by improper bracket placement during orthodontic treatment. Kurth et al. ${ }^{3}$ showed that the mean root angulation in normal gingival embrasures converge at $3.65^{\circ}$ and an increase in root divergence by just $1^{\circ}$ increases the probability of an open gingival embrasure from 14 to $21 \%$. Orthodontic treatment can be performed to converge maxillary incisor roots to reduce or eliminate open gingival embrasures (Figure 4). 


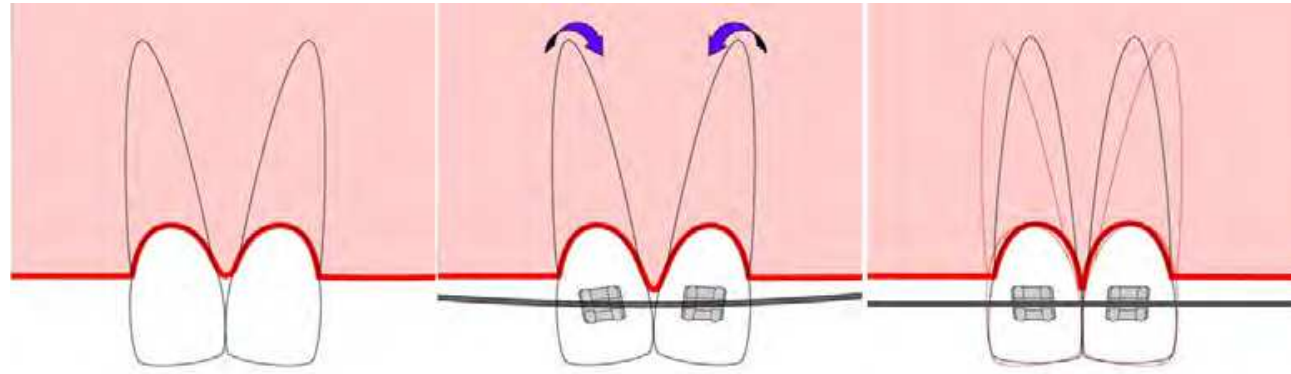

(a)

(b)

(c)

Fig. 4. Paralleling divergent roots will decrease the severity of a black triangle. (a) Divergent roots with an open black triangle. (b) Bracket positioning to follow the long axis of the tooth and correct for black triangle. (c) Converged roots with a closed black triangle after orthodontic treatment.

The bracket slots must be perpendicular to the long axis of the tooth and not parallel to the incisal edges during bracket placement, especially in adults with worn incisal edges. It is important to evaluate the periapical radiograph prior to bracket placement, especially in patients with attrition. ${ }^{15}$ If brackets are placed based on incisal edges, greater root divergence may cause an open gingival embrasure. Bonding brackets with slots perpendicular to the long axis of the teeth will allow roots to converge, and may require the worn distoincisal edges to be restored or contoured. As roots become more parallel, the contact point will lengthen and move apically toward the papilla, thus reducing open gingival embrasures. ${ }^{15}$ The crowns of each incisor will move closer, causing the stretched transseptal fibers to relax and fill in the gingival embrasure. ${ }^{2}$

Patients with triangular crown morphology are more susceptible to open gingival embrasures (Figure 5a). In this case, the crowns of the central incisors are much wider incisally than cervically, resulting in a high contact point. Interproximal reduction (IPR) of enamel between triangular crowns will broaden the point contact area which will reduce open gingival embrasures. Reduction of interproximal enamel with a reducing diamond strip is one way to correct the black triangle. Typically, $0.5-0.75 \mathrm{~mm}$ of enamel is removed with IPR. ${ }^{15}$ Orthodontic space closure after IPR will lengthen the contact point and move the contact gingivally, thus reducing open gingival embrasures (Figures 5b-5d).

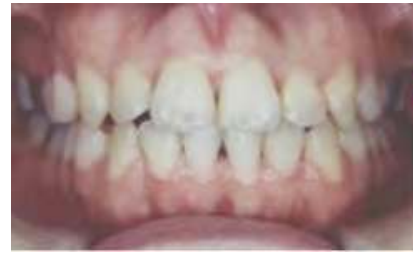

(a)

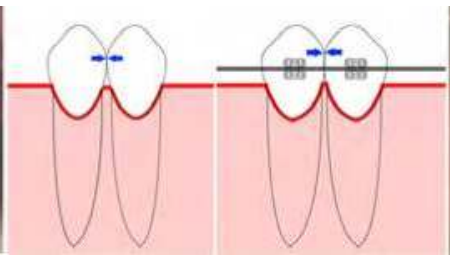

(b)

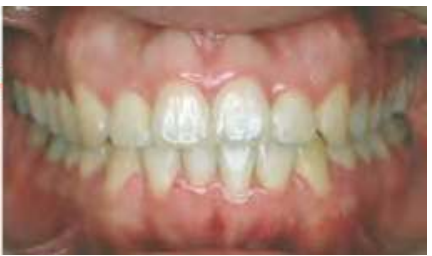

(d)

Fig. 5. (a) Pre-treatment with triangular crowns. Minimizing a black triangle by changing point contact (b) to a broader surface (c) through interproximal reduction (IPR). (d) Posttreatment. 
After orthodontic treatment, the direction of orthodontic tooth movement and labiolingual thickness of the supporting bone and soft tissue determines whether gingival embrasures will be present. Interestingly, maxillary incisor imbrication and rotation have a controversial association with open gingival embrasure spaces.3,6,31 It would be wise to inform patients with imbricated maxillary incisors that they may be predisposed to an open gingival embrasure following orthodontic treatment.

The amount of crowding plays only a limited role in the prevalence of open gingival embrasures. Ko-Kimura et al. ${ }^{1}$ reported that open embrasures occur in a similar percentage of patients with incisor crowding of less than $4 \mathrm{~mm}$ and those with $4-8 \mathrm{~mm}$ of incisor crowding. When crowding was more than $8 \mathrm{~mm}$, the occurrence of open gingival embrasures increased by $7 \%$. However, these results revealed no statistically significant differences. The authors also found that the length of orthodontic treatment had insignificant effect on occurrence of open gingival embrasures.

The volume of soft tissue in the gingival embrasure depends on the existing tissue, bone levels, and the severity of diastema. Closing a diastema by orthodontic treatment compresses the soft tissue, making it fill the embrasure area. Minor diastema closure can be simplified with a removable orthodontic appliance (Figure 6). However, large diastema closure may require more complex treatment with additional orthodontic and/or restorative measures.

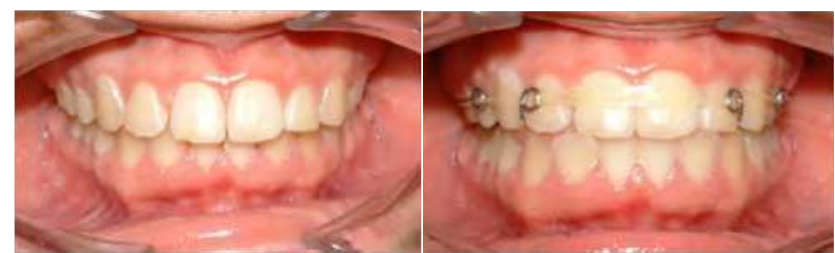

(a) (b)

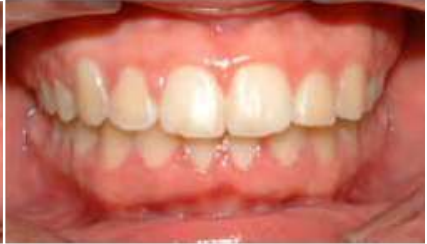

(c)

Fig. 6. Limited orthodontic treatment to close a diastema. (a) Pre-treatment of diastema. (b) A modified maxillary Hawley retainer with extended arms. 3/8", 3.5 oz elastics (3M Unitek, Monrovia, CA, USA) are worn across the teeth from the right arm to the left arm of the retainer. (c) Post-treatment after 4 weeks of treatment.

\section{Restorative correction of open gingival embrasures}

Prosthetic alterations of crown forms by mesiocervical restorations or full veneers will reduce the unaesthetic appearance of open gingival embrasures. To guide the shape of the interdental papilla, composite resin can be extended into the gingival sulcus, much like a provisional crown for an implant. ${ }^{5}$ When restorative measures are used, care must be taken not to impinge on the interdental tissue or harbor plaque. Typically, maxillary central incisors have $80 \%$ width to height ratio, which is considered to be ideal. Simply using a restorative treatment to reduce a large space may cause a divergence of this ratio, resulting in an unaesthetic crown appearance. In this case, an interdisciplinary approach may be necessary.

A connector is the point where teeth appear to contact, and the contact point is the place where they actually do. For restorative treatment to be successful, an appropriate ratio of crown height between the connector and central incisor is required. The connector of maxillary anterior teeth has a proportional relationship to the height of the central incisors. The ratio of connector to tooth height for the central, lateral, and canine is 50,40 , and $30 \%$, 
respectively. ${ }^{32}$ Teeth with longer crown height will have longer connectors (Figure 7). Furthermore, embrasures are smaller between the central incisors and increase progressively toward the posterior region. The application of pink-colored porcelain or a removable appliance is recommended to hide severe tissue defects. ${ }^{2} \mathrm{~A}$ comprehensive understanding of anterior esthetics is critical in determining the appropriate treatment for any individual patient. ${ }^{33-37}$

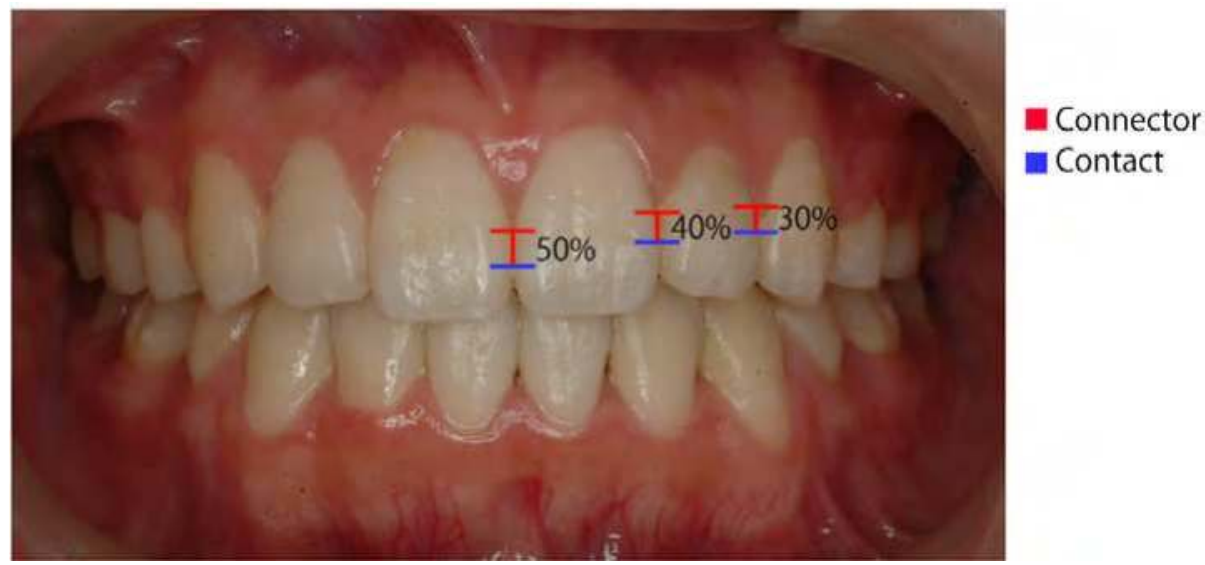

Fig. 7. Connectors and interproximal contact. Connectors (red) are where teeth appear to meet. Contact (blue) between teeth is where they actually meet. The appropriate ratio for a connector between maxillary central incisors is $50 \%$ of the central incisor height. The ratio between central-lateral connectors is $40 \%$ of the central incisor height, and ratio between lateral-canine connectors is $30 \%$ of central incisor height.

\section{Considerations for open gingival embrasures with single tooth implants}

Currently, the single tooth implant is one of the most common treatment alternatives for the replacement of missing teeth. During the treatment planning of single tooth implants to replace congenitally missing lateral incisors, an interdisciplinary approach is preferred to provide the most predictable treatment outcome. Studies have documented successful osseointegration and long term function of restorations supported by single tooth implants. ${ }^{38-41}$ One of the main advantages of this type of restoration is the ability to keep the adjacent teeth intact. However, orthodontic treatment is often necessary to provide adequate room both in the coronal and apical areas.

The biological width of periimplant mucosa is about $2-3 \mathrm{~mm}$; and a similar amount of supracrestal soft tissue is required to allow for the formation of a stable soft tissue attachment and to prevent bone resorption. ${ }^{39}$ Orthodontic treatment should be designed to minimize extrusion of the adjacent teeth because any such movement will have the effect of an apical migration of the implant. ${ }^{38}$ To preserve the interdental papilla and allow for adequate oral hygiene, $1.5-2.0 \mathrm{~mm}$ of space is needed between the implant and the tooth on each side. Therefore, $7 \mathrm{~mm}$ of mesiodistal space must be created between the adjacent teeth. ${ }^{41}$ After the appropriate amount of coronal space has been determined, it is necessary to evaluate the interradicular spacing. The minimum interradicular distance required is 
generally 5-7 mm for a single implant placement. Problems with inadequate space between the root apices are generally due to improper mesiodistal root angulation. When patients with a missing tooth undergo orthodontic treatment, it is important to take a periapical radiograph of the edentulous area prior to removing orthodontic appliances to confirm the ideal root position of the adjacent teeth and adequate spacing for a future implant placement. ${ }^{38}$

A provisional restoration should be placed on the implant to prosthetically guide the soft tissue into its final position. ${ }^{41}$ When a provisional restoration is placed, the subgingival contours and shape of this provisional will influence the position of the soft tissue. ${ }^{42}$ Adding more contour to the facial aspect of the provisional causes the facial free gingival margin to move apically, whereas adding interproximal contour to the provisional helps create a more ideal papillary form. The provisional restoration is generally allowed to remain in place for 4-6 weeks.

The correct buccolingual position of an anterior implant is another important esthetic factor. The head of the implant should be placed inside an imaginary line connecting the incisal margins of the adjacent teeth, so the longitudinal axis of the implant should be $4 \mathrm{~mm}$ from a line tangent to the adjacent occlusal surfaces (Figure 8). In the horizontal plane, the center of the crown placed on the implant should be no farther than half of the abutment radius from the center of the implant - that is approximately $1 \mathrm{~mm}$ in the case of a standard abutment. This location may help to prevent resorption of the thinner cortical buccal bone and consequent recession. ${ }^{43}$ Vertically, the implant platform should be $3-5 \mathrm{~mm}$ apical to the gingival margins of the adjacent teeth to provide a harmonious smile line (Figure 9). An adequate band of attached gingiva also helps reduce the risk of gingival recession.

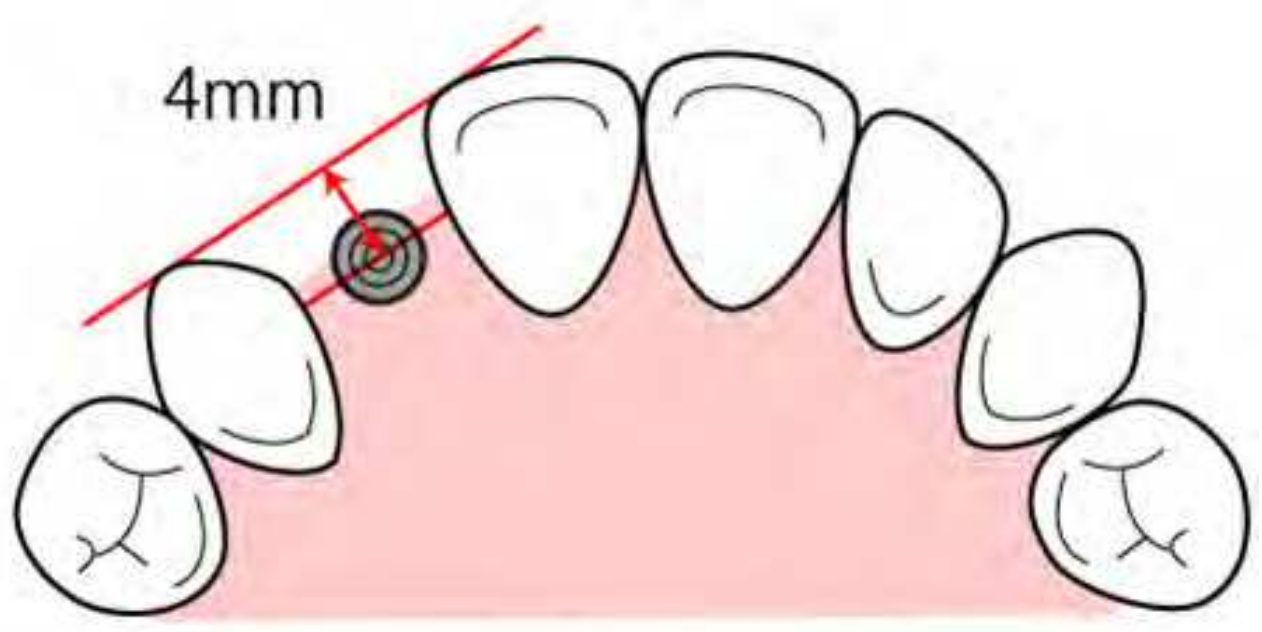

Fig. 8. The longitudinal axis of the implant should be approximately $4 \mathrm{~mm}$ away from an imaginary line connecting the incisal surfaces of the adjacent teeth. 


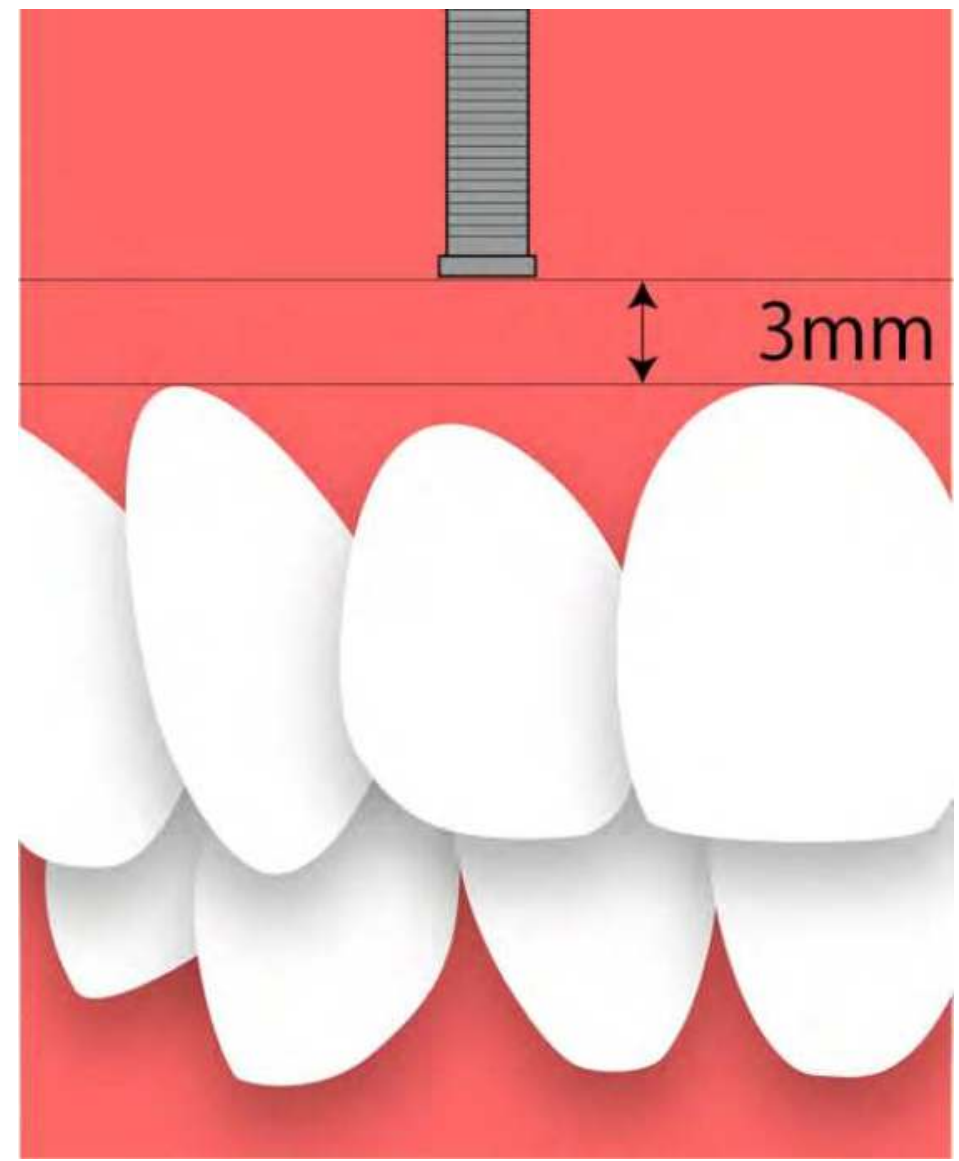

Fig. 9. The implant platform should be $3-5 \mathrm{~mm}$ apical to the gingival margins of the adjacent teeth to provide a harmonious smile line.

Single tooth implants have a significant possibility of papilla loss because of an increase in the distance between the contact point and the alveolar crest.44-46 It is important to keep the distance between the contact point and bone level as $5 \mathrm{~mm}$ or less to preserve papilla around implants. The distance of the adjacent natural teeth to the alveolar crests is the most critical factor, whereas the height of the implant contact to the bone is less important. ${ }^{44}$ Choquet et al. ${ }^{45}$ showed the presence of papilla at $100 \%$ and $50 \%$ level in healthy teeth when the distance from the alveolar crest to the contact point of single implant in the maxillary anterior region was 5 and $6 \mathrm{~mm}$, respectively. A significant increase in black triangles was observed at distances above $7 \mathrm{~mm} .{ }^{28}$ Some clinicians believe that tissue healing around an immediate provisional abutment helps in proper tissue contouring. However, Ryser et al. ${ }^{4}$ stated that there was no difference in papilla loss even if an implant had a provisional placed immediately. Extrusion of a tooth prior to implant placement allows the bone to extrude with the tooth, resulting in an increase in soft tissue dimensions. Tooth extrusion can be performed with intermaxillary elastics and a clear removable appliance such as an 
Essix. ${ }^{47}$ However, existing tissue loss prior to implant placement usually results in an open embrasure following final restoration. Grunder et al. 48 reported a $0.375 \mathrm{~mm}$ increase in soft tissue volume after 1 year, although $0.6 \mathrm{~mm}$ of soft tissue shrinkage occurred on the buccal side of the implant crown. Jemt ${ }^{49}$ also suggested that the volume of soft tissue around anterior single tooth implants can be expected to undergo soft tissue shrinkage on the buccal; whereas, an increase in soft tissue volume occurs in $80 \%$ of cases after 1.5 years.

\section{Considerations for open gingival embrasure with adjacent implants}

In cases where two implants are placed adjacent to each other, open gingival embrasures are more pronounced. Up to $4 \mathrm{~mm}$ of vertical alveolar bone may be lost in such cases. ${ }^{50}$ Fibers are stretched vertically instead of perpendicularly from the implant surface and there is reduced blood supply, further complicating papilla restoration.51 A soft tissue deficiency of 1-2 mm occurs because the biological width around an implant is apical to the platform for the abutment. ${ }^{2}$ As a result, the biological width of implants is located subcrestally rather than the supracrestal location with natural teeth. ${ }^{43}$ The distance between the implant shoulder and alveolar crest should be at least $4 \mathrm{~mm}$ in the maxillary anterior region. To prevent bone loss and subsequent papilla loss, it is important that the distance between two adjacent implants exceeds $3 \mathrm{~mm} .{ }^{44}$ This helps to maintain interproximal bone above the implant shoulder. In the anterior region, it is usually difficult to achieve this ideal mesiodistal distance between implants. One way to compensate for the loss of interproximal bone is to augment the buccal bone in the papillary area, ${ }^{53,54}$ but it is not possible to ensure a complete papilla with distances greater than $3 \mathrm{~mm}$. There are several procedures that may help to prevent additional interproximal bone loss but they won't allow papilla regeneration. When placing and restoring adjacent immediate implants, papilla is better preserved if the distance is $2-4 \mathrm{~mm} .55$ To prevent unaesthetic open embrasures in the esthetic zone, adjacent implants should better be avoided. Options for two missing teeth in the esthetic zone include orthodontic movement of teeth, placing an implant with a cantilever pontic and performing a soft tissue graft, interproximal bone augmentation, or a three unit bridge involving one implant. 46

\section{Summary}

The distance between the alveolar crest and interproximal contact point together with periodontal bone loss appear to be the most significant factors contributing to occurrence of open gingival embrasures. The etiology of open gingival embrasures is multifactorial, so to determine the ideal treatment for the patient, the clinician should first evaluate whether the problem is caused by soft or hard tissue problem. An interdisciplinary team approach including a general dentist, an orthodontist, a periodontist, and a prosthodontist should be considered for the optimum restoration of open gingival embrasures.

\section{References}

[1] Ko-Kimura N, Kimura-Hayashi M, Yamaguchi M, et al. Some factors associated with open gingival embrasures following orthodontic treatment. Aust Orthod J. 2003;19(1):19-24. 
[2] Tarnow DP, Magner AW, Fletcher P. The effect of the distance from the contact point to the crest of bone on the presence or absence of the interproximal dental papilla. $J$ Periodontol. 1992;63(12):995-996.

[3] Kurth JR, Kokich VG. Open gingival embrasures after orthodontic treatment in adults: prevalence and etiology. Am J Orthod Dentofacial Orthop. 2001;120(2):116-123.

[4] Kokich VO Jr, Kiyak HA, Shapiro PA. Comparing the perception of dentists and lay people to altered dental esthetics. J Esthet Dent. 1999;11(6):311-324.

[5] Clark D. Correction of the "black triangle": restoratively driven papilla regeneration. Dent Today. 2009;28(2):150, 152, 154-155.

[6] Burke S, Burch JG, Tetz JA. Incidence and size of pretreatment overlap and posttreatment gingival embrasure space between maxillary central incisors. Am J Orthod Dentofacial Orthop. 1994;105(5):506-511.

[7] Chang LC. Effect of bone crest to contact point distance on central papilla height using embrasure morphologies. Quintessence Int. 2009;40(6):507-513.

[8] Becker W. Commentary. Esthetic considerations in interdental papilla: remediation and regeneration. J Esthet Restor Dent. 2010;22(1):29-30.

[9] Theytaz GA, Kiliaridis S. Gingival and dentofacial changes in adolescents and adults 2 to 10 years after orthodontic treatment. J Clin Periodontol. 2008;35(9):825-830.

[10] Sharma AA, Park JH. Esthetic considerations in interdental papilla: remediation and regeneration. J Esthet Restor Dent. 2010;22(1):18-28.

[11] Ikeda T, Yamaguchi M, Meguro D, Kasai K. Prediction and causes of open gingival embrasure spaces between the mandibular central incisors following orthodontic treatment. Aust Orthod J. 2004;20(2):87-92.

[12] Cardaropoli D, Re S. Interdental papilla augmentation procedure following orthodontic treatment in a periodontal patient. J Periodontol. 2005;76(4):655-661.

[13] Chang LC. The association between embrasure morphology and central papilla recession. J Clin Periodontol. 2007;34(5):432-436.

[14] Zetu L, Wang HL. Management of inter-dental/inter-implant papilla. J Clin Periodontol. 2005;32(7):831-839.

[15] Wu YJ, Tu YK, Huang SM, Chan CP. The influence of the distance from the contact point to the crest of bone on the presence of the interproximal dental papilla. Chang Gung Med J. 2003;26(11):822-828.

[16] Chang LC. Assessment of parameters affecting the presence of the central papilla using a non-invasive radiographic method. J Periodontol. 2008;79(4):603-609.

[17] Prato GPP, Rotundo R, Cortellini P, Tinti C, Azzi R. Interdental papilla management: a review and classification of the therapeutic approaches. Int J Periodontics Restorative Dent. 2004;24(3):246-255.

[18] Tanaka OM, Furquim BD, Pascotto RC, et al. The dilemma of the open gingival embrasure between maxillary central incisors. J Contemp Dent Pract. 2008;9(6):92-98.

[19] Ravon NA, Handelsman M, Levine D. Multidisciplinary care: periodontal aspects to treatment planning the anterior esthetic zone. J Calif Dent Assoc. 2008;36(8):575584 . 
[20] Lee DW, Kim CK, Park KH, Cho KS, Moon IS. Non-invasive method to measure the length of soft tissue from the top of the papilla to the crestal bone. J Periodontol. 2005;76(8):1311-1314.

[21] Azzi R, Takei HH, Etienne D, Carranza FA. Root coverage and papilla reconstruction using autogenous osseous and connective tissue grafts. Int J Periodontics Restorative Dent. 2001;21(2):141-147.

[22] Oringer RJ, Iacono VJ. Current periodontal plastic procedures around teeth and dental implants. N Y State Dent J. 1999;65(6):26-31.

[23] Blatz MB, Hürzeler MB, Strub JR. Reconstruction of the lost interproximal papillapresentation of surgical and nonsurgical approaches. Int J Periodontics Restorative Dent. 1999;19(4):395-406.

[24] van der Velden U. Regeneration of the interdental soft tissues following denudation procedures. J Clin Periodontol. 1982;9(6):455-459.

[25] Roy BJ. Improving prosthetic results through periodontal procedures. J Indiana Dent Assoc. 1998;77(1):17-20, 33-35.

[26] Checchi L, Montevecchi M, Checchi V, Bonetti GA. A modified papilla preservation technique, 22 years later. Quintessence Int. 2009;40(4):303-311.

[27] Nemcovsky CE. Interproximal papilla augmentation procedure: a novel surgical approach and clinical evaluation of 10 consecutive procedures. Int J Periodontics Restorative Dent. 2001;21(6):553-559.

[28] Olsson M, Lindhe J, Marinello CP. On the relationship between crown form and clinical features of the gingiva in adolescents. J Clin Periodontol. 1993;20(8):570-577.

[29] Chow YC, Wang H-L. Factors and techniques influencing peri-implant papillae. Implant Dent. 2010;19(3):208-219.

[30] Chang L-C. The association between embrasure morphology and central papilla recession: a noninvasive assessment method. Chang Gung Med J. 2007;30(5):445-452.

[31] Kandasamy S, Goonewardene M, Tennant M. Changes in interdental papillae heights following alignment of anterior teeth. Aust Orthod J. 2007;23(1):16-23.

[32] Raj V, Heymann HO, Hershey HG, Ritter AV, Casko JS. The apparent contact dimension and covariates among orthodontically treated and nontreated subjects. J Esthet Restor Dent. 2009;21(2):96-111.

[33] Cardaropoli D, Re S, Corrente G. The Papilla Presence Index (PPI): a new system to assess interproximal papillary levels. Int $J$ Periodontics Restorative Dent. 2004;24(5):488-492.

[34] Martegani P, Silvestri M, Mascarello F, et al. Morphometric study of the interproximal unit in the esthetic region to correlate anatomic variables affecting the aspect of soft tissue embrasure space. J Periodontol. 2007;78(12):2260-2265.

[35] Sarver DM. Principles of cosmetic dentistry in orthodontics: Part 1. Shape and proportionality of anterior teeth. Am J Orthod Dentofacial Orthop. 2004;126(6):749753.

[36] Kokich VG. Esthetics and vertical tooth position: orthodontic possibilities. Compend Contin Educ Dent. 1997;18(12):1225-1231.

[37] Kokich V. Esthetics and anterior tooth position: an orthodontic perspective. Part III: Mediolateral relationships. J Esthet Dent. 1993;5(5):200-207. 
[38] Thilander B, Odman J, Jemt T. Single implants in the upper incisor region and their relationship to the adjacent teeth. An 8-year follow-up study. Clin Oral Implants Res. 1999;10(5):346-355.

[39] Goldberg PV, Higginbottom FL, Wilson TG. Periodontal considerations in restorative and implant therapy. Periodontol 2000. 2001;25(1):100-109.

[40] Noack N, Willer J, Hoffmann J. Long-term results after placement of dental implants: longitudinal study of 1,964 implants over 16 years. Int J Oral Maxillofac Implants. 1999;14(5):748-755.

[41] Zuccati G. Implant therapy in cases of agenesis. J Clin Orthod. 1993;27(7):369-373.

[42] Senty EL. The maxillary cuspid and missing lateral incisors: esthetics and occlusion. Angle Orthod. 1976;46(4):365-371.

[43] Adell R, Eriksson B, Lekholm U, Brånemark PI, Jemt T. Long-term follow-up study of osseointegrated implants in the treatment of totally edentulous jaws. Int J Oral Maxillofac Implants. 1990;5(4):347-359.

[44] Ryser MR, Block MS, Mercante DE. Correlation of papilla to crestal bone levels around single tooth implants in immediate or delayed crown protocols. J Oral Maxillofac Surg. 2005;63(8):1184-1195.

[45] Choquet V, Hermans M, Adriaenssens P, et al. Clinical and radiographic evaluation of the papilla level adjacent to single-tooth dental implants. A retrospective study in the maxillary anterior region. J Periodontol. 2001;72(10):1364-1371.

[46] Tarnow D, Elian N, Fletcher P, et al. Vertical distance from the crest of bone to the height of the interproximal papilla between adjacent implants. J Periodontol. 2003;74(12):1785-1788.

[47] Park JH, Kim TW. Open-bite treatment utilizing clear removable appliances with intermaxillary and intramaxillary elastics. World J Orthod. 2009;10(2): 130-134.

[48] Grunder U, Gracis S, Capelli M. Influence of the 3-D bone-to-implant relationship on esthetics. Int J Periodontics Restorative Dent. 2005;25(2):113-119.

[49] Jemt T. Regeneration of gingival papillae after single-implant treatment. Int J Periodontics Restorative Dent. 1997;17(4):326-333.

[50] Lekovic V, Kenney EB, Weinlaender M, et al. A bone regenerative approach to alveolar ridge maintenance following tooth extraction. Report of 10 cases. J Periodontol. 1997;68(6):563-570.

[51] Pradeep AR, Karthikeyan BV. Peri-implant papilla reconstruction: realities and limitations. J Periodontol. 2006;77(3):534-544.

[52] Tarnow DP, Cho SC, Wallace SS. The effect of inter-implant distance on the height of inter-implant bone crest. J Periodontol. 2000;71(4):546-549.

[53] Grunder U. Stability of the mucosal topography around single-tooth implants and adjacent teeth: 1-year results. Int J Periodontics Restorative Dent. 2000;20(1): 11-17.

[54] Grunder U, Spielman HP, Gaberthüel T. Implant-supported single tooth replacement in the aesthetic region: a complex challenge. Pract Periodontics Aesthet Dent. 1996;8(9):835-842. 
[55] Degidi M, Novaes AB Jr, Nardi D, Piattelli A. Outcome analysis of immediately placed, immediately restored implants in the esthetic area: the clinical relevance of different interimplant distances. Periodontol. 2008;79(6):1056-1061. 


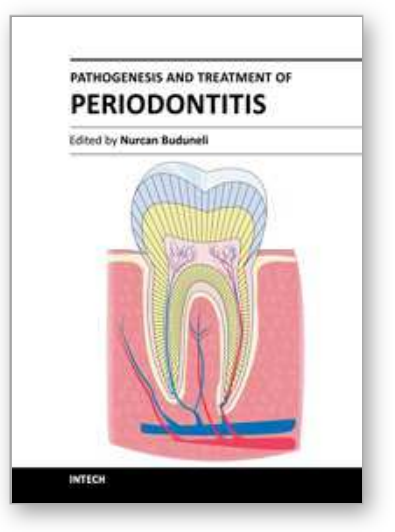

\author{
Pathogenesis and Treatment of Periodontitis \\ Edited by Prof. Nurcan Buduneli
}

ISBN 978-953-307-924-0

Hard cover, 200 pages

Publisher InTech

Published online 20, January, 2012

Published in print edition January, 2012

Pathogenesis and Treatment of Periodontitis includes comprehensive reviews on etiopathogenic factors of periodontal tissue destruction related to microbial dental plaque and also host response components. Adjunctive treatment modalities are also addressed in the book. Topics covered range from microbial pathogenic factors of $\mathrm{P}$. gingivalis to the relationship between metabolic syndrome and periodontal disease, and from management of open gingival embrasures to laser application in periodontal treatment.

\title{
How to reference
}

In order to correctly reference this scholarly work, feel free to copy and paste the following:

Jae Hyun Park, Kiyoshi Tai, John Morris and Dorotea Modrin (2012). Clinical Considerations of Open Gingival Embrasures, Pathogenesis and Treatment of Periodontitis, Prof. Nurcan Buduneli (Ed.), ISBN: 978-953-307924-0, InTech, Available from: http://www.intechopen.com/books/pathogenesis-and-treatment-ofperiodontitis/clinical-considerations-of-open-gingival-embrasures

\section{INTECH}

open science | open minds

\section{InTech Europe}

University Campus STeP Ri

Slavka Krautzeka 83/A

51000 Rijeka, Croatia

Phone: +385 (51) 770447

Fax: +385 (51) 686166

www.intechopen.com

\section{InTech China}

Unit 405, Office Block, Hotel Equatorial Shanghai

No.65, Yan An Road (West), Shanghai, 200040, China 中国上海市延安西路65号上海国际贵都大饭店办公楼 405 单元

Phone: +86-21-62489820

Fax: $+86-21-62489821$ 
(C) 2012 The Author(s). Licensee IntechOpen. This is an open access article distributed under the terms of the Creative Commons Attribution 3.0 License, which permits unrestricted use, distribution, and reproduction in any medium, provided the original work is properly cited. 